\title{
Transition of care for the elderly after cerebrovascular accidents - from hospital to the home
}

\author{
Rosalina Aparecida Partezani Rodrigues ${ }^{1}$ \\ Sueli Marques ${ }^{2}$ \\ Luciana Kusumota ${ }^{2}$ \\ Emanuella Barros dos Santos ${ }^{3}$ \\ Jack Roberto da Silva Fhon ${ }^{4}$ \\ Suzele Cristina Coelho Fabrício-Wehbe ${ }^{5}$
}

Objective: to examine the transition of care in families caring for elderly persons who suffered the first episode of a cerebrovascular accident. Methodology: an instrumental ethnographic case study was used. The sample comprised 20 subjects: 10 caregivers and 10 elderly persons aged 65 or over, of both sexes, with diagnoses of first episode of cerebrovascular accident, capable of communicating, and requiring care from a main carer in their family. The data was collected through interviews, observation, existing documentation and field notes. Qualitative analysis techniques were used to codify and classify the data and to formulate significant categories, which generated typologies of care. Results and Discussion: The central idea was the Transition of Care and showed the context in three typologies: The care process for the dependent elderly person, Strategies for the care process and Impact and acceptance of the limitations. Conclusion: The data indicates that caring for an elderly person after a cerebrovascular accident is a challenge for the family. The data permitted it possible to elaborate a proposal for a model for the organization of the work, with a view to holistic care delivery in the health services, forming a care network, which constitutes an advance for the area of nursing.

Descriptors: Aged; Stroke; Family; Caregivers; Geriatric Nursing.

\footnotetext{
${ }^{1}$ PhD, Full Professor, Escola de Enfermagem de Ribeirão Preto, Universidade de São Paulo, WHO Collaborating Centre for Nursing Research Development, Brazil.

2 PhD, Professor, Escola de Enfermagem de Ribeirão Preto, Universidade de São Paulo, WHO Collaborating Centre for Nursing Research Development, Brazil.

${ }^{3}$ Master's Student, Escola de Enfermagem de Ribeirão Preto, Universidade de São Paulo, WHO Collaborating Centre for Nursing Research Development, Brazil.

${ }^{4}$ MSc, Professor, Universidad Privada Norbert Wiener, Peru.

${ }^{5} \mathrm{PhD}$, Professor, Centro Universitário Barão de Mauá, Brazil.
}

Corresponding Author:

Rosalina Aparecida Partezani Rodrigues

Universidade de São Paulo. Escola de Enfermagem de Ribeirão Preto

Av. Bandeirantes, 3900

Bairro Monte Alegre

CEP: 14040902, Ribeirão Preto, SP, Brasil

E-mail: rosalina@eerp.usp.br 


\title{
Transição do cuidado com o idoso após acidente vascular cerebral do hospital para casa
}

Objetivo: examinar a transição do cuidado em famílias que cuidam de idosos que sofreram o primeiro episódio de acidente vascular cerebral. Metodologia: foi utilizado o estudo de caso etnográfico instrumental. A amostra foi constituída por 20 sujeitos, sendo 10 cuidadores e 10 idosos, com 65 anos ou mais, de ambos os sexos, com diagnóstico de primeiro episódio de acidente vascular cerebral, capazes de se comunicarem, demandando cuidado de um cuidador principal na família. Os dados foram coletados por meio de entrevistas, observações, documentos existentes e notas de campo. Foram utilizadas técnicas de análises qualitativa para codificar, classificar os dados e formular categorias significativas, o que gerou tipologias de cuidado. Resultados e Discussão: a ideia central foi a transição do cuidado e mostrou o contexto em três tipologias: o processo de cuidar do idoso dependente, estratégias para o processo de cuidar e impacto e aceitação das limitações. Conclusão: os dados indicaram que o cuidado com o idoso, após o acidente vascular cerebral, é um desafio para a família. Os dados possibilitaram elaborar uma proposta de modelo para a organização do trabalho, visando a integralidade do cuidado nos serviços de saúde, formando uma rede de cuidado, o que constitui avanço para a área da enfermagem.

Descritores: Idoso; Acidente Vascular Cerebral; Família; Cuidadores; Enfermagem Geriátrica.

\section{Transición del cuidado del adulto mayor despues del accidente cerebral vascular del hospital para casa}

\begin{abstract}
Objetivo: examinar la transición del cuidado en familias que cuidan de adultos mayores que sufrieron el primer episodio de accidente cerebral vascular. Metodología: Fue utilizado el estudio de caso etnográfico instrumental. La muestra fue constituida de 20 sujetos, siendo 10 cuidadores y 10 adultos con 65 años y más, de ambos sexos, con diagnóstico de primer episodio de accidente cerebral vascular, capaces de comunicarse, demandando cuidado de un cuidador principal en la familia. Los datos fueron colectados por medio de entrevistas, observaciones, documentos existentes y notas de campo. Fueron utilizadas las técnicas de análisis cualitativo para codificar, clasificar los datos y formular categorías significativas, lo que generó tipologías de cuidado. Resultados y Discusión: La idea central fue la transición del cuidado y mostró el contexto en tres tipologías: El proceso de cuidar del adulto mayor dependiente, Estrategias para el proceso de cuidar e Impacto y aceptación de las limitaciones. Conclusión: Los datos nos indicaron que el cuidado para el adulto mayor, después del accidente cerebral vascular es un desafío para la familia. Los datos posibilitaron elaborar una propuesta de modelo para la organización del trabajo, visando la integralidad del cuidado en los servicios de salud, formando una red de cuidado, lo que representa un avance para el área de enfermería.
\end{abstract}

Descriptores: Anciano; Accidente Cerebrovascular; Família; Cuidadores; Enfermería Geriátrica.

\section{Introduction}

Cerebrovascular accidents (CVA) are responsible for approximately 5.5 million deaths annually worldwide ${ }^{(1-2)}$. Around 16 million people suffered an episode of CVA, for the first time, in 2005, with an estimated prevalence of 6.2 million survivors ${ }^{(2-3)}$.

In Brazil, in the period 2008 to 2011, there were 424,859 hospitalizations of elderly persons aged 60 years old or more due to CVA, with a mortality rate of 18.32. In the state of São Paulo 69,722 hospitalizations occurred, with a mortality rate of 18.57 . In the same period, within the state of São Paulo in the municipality of Ribeirão Preto, it was ascertained that 1,645 elderly persons were hospitalized ( 820 women and 817 men), with an average period of hospitalization of 7.1 days and a mortality rate of $16.41^{(4)}$. This data reaffirms the seriousness of the problem in this age range and the need for special attention to the issue, because it is the most prevalent cerebrovascular illness in the elderly 
population. Its incidence increases exponentially as age advances, and it is considered one of the major causes of disability in this population (5-7).

Functional incapacity can create difficulties for the elderly in carrying out daily activities which may be transcient or permanent, depending on the region of the brain affected, the level of the lesion and the individual capacity for recuperation following the CVA. These difficulties can lead to reduction in quality of life with an impact on the everyday routine of the elderly persons and their families ${ }^{(8)}$. The degree of the patient's incapacities determine the levels of dependency on care and, consequently, the challenge to the family caregiver ${ }^{(8-9)}$, because the elderly person will need prolonged care. After discharge from hospital, the elderly person may have a series of limitations, including behavioral changes and changes in roles to be developed in the family, in society and in the self itself.

Once the patient has returned home, the care's perspective differs from in hospital; it is in this moment that the transition from the 'cure phase' to the 'case process' at home takes place. Authors report that the transition is the passage from one phase of life to another, in the face of various conditions or status, in a particular social context(10). It is in this moment of transition in the elderly person's health - towards recuperation and selfcare - that the family, as a social institution, deals with the changes, both in functional abilities and in the body image of the CVA survivor(11). It is observed that in this transition, the process of caring for the elderly person depends on the society's culture and on the family itself. Each family devises this care, which was constructed over time with its knowledge, habits, customs, language, beliefs, family environment and network of relationships constructed with the elderly person.

The interpretation of a culture of which one is part must be deduced(12). By nature, humans have the potential to care for themselves and for others within their cultural universe(13). This care has always existed and is a challenge society faces in caring for family members. Even with the availabiliy of lighter technology, the family's difficulties in dealing with the condition of dependency arising from an illness remain. These difficulties affect the entire family dynamic.

One of the strategies for responding to the challenges to health care in the population of persons who have suffered CVA is to investigate - in partnership with the elderly persons and their families - the description, in depth, of this caring process, so as to implement a care plan. Furthermore, it becomes necessary to refer the elderly person so that the health team may act in partnership with the family in this process.

It is worth emphasizing the scarcity of the literature on this issue, which justifies the need for undertaking research to deepen knowledge of the topic and, also, the need to support the nurse on the subject of the requirements of caring for the elderly following CVA and, consequently, to support the nurse by developing a care plan which is integrated with the family.

In the face of the above considerations, this study aims to examine the transition of the care for the elderly person and the families which care for elderly persons who have suffered the first episode of CVA, from the perspective of the culture constructed by the family.

\section{Method}

An instrumental ethnographic case study was used, because the objective was to examine the transition of care in families caring for 10 elderly persons who had suffered the first episode of CVA, attended in the Emergency Department of a hospital in Ribeirão Preto in the state of São Paulo, Brazil. The case study describes the contemporaneous experience and the historical events, and both are used to narrate, represent and to examine situations which emerge from the people's lives and which must be taken into account from the perspective of the ethnographic method(14). The focus of interest was on knowing and interpreting how the process of caring for the elderly person after a stroke worked out, following discharge from hospital.

The research process started with the identification of the elderly persons who had suffered a CVA; for this reason, the collection took place in the first semester of 2011, through analysis of documents, semi-structured intervews and observation. For this, contact was made beforehand by telephone with the elderly person/family for arranging a visit at their home, respecting their availability, explaining the objective of the research and the need for their consent to participate, as the researcher has to apprehend the situations from daily life.

The interviews followed the sequence: identification of the elderly and the caregivers, evaluation of cognitive state, Mini Mental State Examination and evaluation of functional independence (Functional Independence Measure) and the following guiding question: How do you care for the elderly person after the stroke?The interviews were recorded and used to obtain reliable descriptions about the care, how the CVA occurred, the transition from hospital to home, and, also, to describe 
the subjects' knowledge about activities, events and other situations observed during the visit.

The interviews were transcribed on a word processing program for data encoding and inductive thematic analysis(15); the ALCESTE (Lexical analysis by context of a set of segments of text) program was used for the search for the topics, refining and final production of the main categories derived from the data extracted from the study.

This process of transition brought the authors to a proposal of a model of care which reflects the nature and the meaning of the events of health and care for the families of elderly persons who have had a CVA.

The project was approved by the Ethics Committee of the General Teaching Hospital of the Faculty of Medicine of Ribeirão Preto (University of São Paulo), under process $n^{\circ} 1952 / 2010$. The Terms of Free and Informed Consent were signed by the elderly person and by the family caregiver.

\section{Data analysis}

\section{Characterization of the Elderly Person}

10 elderly persons participated in the study, 50\% female and $50 \%$ male, aged between 67 and 89 years old, with an average of 77.5 years; $100 \%$ of the women were widows and $30 \%$ of the men were married. The majority of the women lived with their children, while the men lived with people to whom they were not related. Their income varied from 1 to 3 minimum salaries and the majority of the elderly were illiterate. The average number of children was 3.6. Regarding the type of CVA, $10 \%$ were hemorrhagic and $90 \%$ ischemic, with an average period of hospitalization of 11.9 days.

The average score on the Mini-Mental State Examination was 20.1 points, which demonstrates that the elderly persons were able to respond to the questions. Regarding the Functional Independence Measure (FIM), the total FIM varied between the men (from 26 to 125) and the women (from 43 to 102); the FIM Motor subscale among the men varied from 13 to 91 , and in the women, from 22 to 69, while the FIM Cognitive scale among the men varied from 13 to 34 , and among the women from 18 to 34. In the evaluation observed, it may be ascertained that the elderly were to be found in the levels between dependency and some state of independence.

All of the elderly who had suffered strokes had caregivers, $100 \%$ of whom were female. $70 \%$ of these were the elderly persons' married daughters, aged between 34 and 82 years old.
The dynamics of the transition of care for the elderly person

The data were obtained from the corpus corresponding to the 20 interviews or Initial Context Units (ICU's), submitted to analysis with the help of the Alceste 2010 software and it was ascertained that, of the 298 present in the corpus, 190 ICU's were maintained, corresponding to $62.09 \%$. The analysis points to three major typologies of care: The first is defined by the formation of the classes 1,4 and 6 and their respective ICU's: class 1 - Dependency of the elderly person and of the caregiver for the care, comprised of 26 ICU's (13.68\%); class 4 - Help from others for caring, with 24 ICU's (12.63\%), and class 6 - The caregiver's role - made up of 18 ICU's (9.47\%), together forming Typology 1: The process of caring for the dependent elderly person. The second typology is associated with the first and with class 2 - Psychosocial aspects of care and changes in the family's routines, with 29 ICU's (15.26\%) and with class 3 - Strategies used by the caregiver in caregiving, defined by 26 ICU's $(13.68 \%)$, characterized by Typology 2: Strategies for the process of care. The third, is formed by the first two axes associated with class 5 -. Impact and acceptance of the limitations, with 67 ICU's (3.26\%), with Typology 3 being: Impact and acceptance of the limitations.

\section{Typology 1: The process of caring for the dependent elderly person}

The observation of and dialog with the caregivers about the care of the elderly person showed that the health system transfers the responsibility to the family without, however, making the transition for this care in partnership. The hospital is a station from the perspective of integrality of care(16), but how should one think about the continuity in the care process in the elderly person's home after the CVA? How does the family organize this care? What are each elderly person's needs? Why does the family need help? These questions are fundamental if this "hidden" help from the family is to be shared with the health team.

The occurrence of the CVA may mean to the elderly person that his or her physical integrity was affected. In addition, the hospitalization includes different environments and routines and different relationships, among others. Thus, it is a difficult period for the elderly person, principally regarding physical and psychosocial dependence. This is when the health team has control over the elderly person's body, because of the limitation 
on activities of daily living, principally on mobility. It is in this context that the role of the clinical nurse must be to find out about the family's culture of care, so that in this process of transition, the experience with this may foster interaction, so that this process of caring for elderly persons in a more vulnerable condition may occur.

The experience of the dependence allows the elderly person to unveil the context that he or she was experiencing, that is, the need for care after the CVA. The first issue which emerged was the dependence that the elderly had in the face of difficulties in self-care, and also, which the caregivers themelves had in providing this care, as in the following account ...she used to be an extremely active person, very hardworking, until three months ago she was washing clothes, cooking, and now she's like this... unable to move or walk... (Caregiver 2).

Another issue emphasized is the caregiver's dependency for learning how to provide care, as in this account: I couldn't do it right..., we gave her a bath, as she was, we got her changed... only we think we hurt her, we hurt her arm, I think. My brother-in-law was here, he got here out and put her in bed. You...putting a nappy on a baby is one thing, but on an adult is another. The other care activities are easier, like cooking for her, preparing things for her, for me that's easy, no problem there. (Caregiver 3 ).

Human beings, by nature, have the potential to care for themselves and for others within their cultural universe. Although this caregiving has always existed, it is a challenge for a family to care for a person whose dependency has been imposed by an illness, even with the aid of a wide range of technology; which ends up affecting the family dynamics ${ }^{(13)}$.

While the elderly person is hospitalized, the care is given by the nursing team. When the elderly person returns home, however, the transition of care occurs, that is, the family assumes responsibility for the care, as part of the dynamic which goes from "curing the illness" to "caring for the elderly person", in a more global context, with a view to recuperation. This care, "hidden", interwoven with easy and/or complex tasks, produced a certain fear in the family members, due to the lack of knowledge; thus, the family needed careful attention from the health team at the time of discharge, at the same time as it was thinking about the possibility of the approach of the death of a loved one. In this way, the understanding of the routine in the elderly person's home and of how the family functions, for interpreting and analyzing the context, must be based on a framework which makes this task possible.
According to the accounts, the families have difficulties in providing the care to the elderly, most of whom have sequelae, even in the psychosocial area. Thus, it was noted that it was not only situations related to functional limitations that families had to manage; in addition, over the time the care is given, some elderly exhibit greater or lesser dependence and the ways that care is provided become organized, because the caregivers seek their own strategies for carrying out the care. The families themselves gradually learned the ways of caring and how each member's roles should be defined throughout the trajectory of this process. Despite there being a health policy which determines the system of referral and counter-referral, the health care network, whose center is Primary Care, still has weak points in caring for the elderly person who suffers a stroke and needs to be cared for by the family at home.

The literature shows that the occurrence of CVA affects the life of other members of the family and that this process may be considered chaotic, resulting in changes in family relationships and burnout in the caregivers dealing with this situation, until it attains a new phase of reorganization ${ }^{(17)}$.

The accounts also evidenced changes in family relationships after an elderly person's CVA - the caregiver looking sad, having red eyes and some tears when she referred to the distancing and/or absence of siblings in her daily life. The lack of support and the presence of family members seemed something which affected her more than her mother's illness itself, in Caregiver 2's account: ... I have my brothers, but...the relationship with Mom and with us worsened after the illness...nobody wants to help when you need it, when there are financial difficulties, even when you need tenderness. In addition, the elderly person's dependence causes a certain fear in the family: ... when she was in hospital, my aunts went there...but not here, at home. ...I have to care for her on my own.. the weight and the burden are heavy....(Caregiver 4).

It may be observed that the informal health care network - family, friends and neighbors - is organized around the family member's care needs, although without knowledge of the process of confronting the care situations. In this respect, the forming of care networks should be systematized by Primary Care.

In the process of implanting the Unified Health Service (SUS), the work of the nurse in Primary Care involves administration, the organization of the work of health and nursing, but clinical actions for system users still need to be discussed and implemented, there being a need for formal spaces for the work of the nurse for carrying out these actions ${ }^{(18)}$. 


\section{Typology 2: Strategies for the care process}

One of the aspects observed in the present study is that the socio-familial contexts are diverse, and that the relationship and care histories were reconstructed over the period of their formation. Thus, one must consider not only the care given after the CVA, but also the context into which the families are inserted. In the process of caring for an elderly person with difficulties in self-caring, the family learns with the patient, organizing itself, and new ways of caring appear, as was related: ...I think that this experience is difficult...an adult knows how to care for themselves, but with the illness, the family needs to learn... it's an obligation and a test for us. We are learning to provide care, as the family teaches (Caregiver 5).

A study with stroke survivors showed that in the period of transition from hospital to home, the following stood out: changes in the sense of self and body experiences, changes in the relationship with others and in one's integration in the community(17), which corroborates the findings of the present research, in which after the CVA the elderly person's relationship with the caregiver brings the family together, in some phases of the transition; other changes cause situations of conflict, as in the account:...the impact is this! It's very painful... the changes in the family relationships in how her children and grandchildren relate to her, after the stroke... The stroke impacted on the relationships in the family, because of her needs, the needs from her pain, her need to remain lying down, the need to care for her diabetes. So, the stroke brought us closer... I only used to see my mother from time to time, but not now, we're together all the time... because of the illness and the need to care for her...(Caregiver 1 ).

In the period of transition, there may occur a phase of changes in family relationships, very often followed by a reorganization of the family system to manage this care ${ }^{(19)}$. The literature describes few experiences of how the family manages the care for the elderly person after the CVA ${ }^{(5)}$; however, the experience of caring for a family member, at home, is constructed over time, which may be observed in the account from Caregiver 7: ... everybody's life changed after the stroke, because he can't walk, can't talk, because of everything, because everything changes, the change comes, it comes along with the stroke, it comes... with the dependence.

The transition is a process which occurs over time, that is, it involves the interruption of a given situation in a person's life, while the second phase involves the changes which occur as a result of this transition(20). Particularly in this study, the elderly persons who suffered CVA are subject to a series of interruptions which entail the implementation of new strategies for reorganizing the care, in the face of functional and emotional losses, irrespective of how the care was learnt.

The caregivers' experiences in caring for patients who had suffered CVA, in the phase of transition from hospital home, show the need for important training so that they can manage this process. The strategies may be divided into: aspects involving society, the system of care, and the person involved in this process ${ }^{(21)}$.

The aspects of society involve the allocation of financial resources for this transition of care, principally because of the health problems appearing with the CVA. In Brazil, this discussion still needs effective debates for its implementation; in the care system the work of the multidisciplinary team, including the nurse, must be implemented, supervised and assessed; however, this work is still undertaken piecemeal, as there is no continuity in this care involving the family. In the specific case of the elderly in the present study, what was observed in the accounts of the caregivers and the elderly themselves was the difficulty even in the first attendance by the health centers. There was one situation in which the elderly person... was attended and didn't receive the appropriate treatment, being attended on another occasion by another health professional who did the necessary referral... in the light of his symptoms... (Caregiver 8).

The last strategy is the individual, in which family provide the care and various situations are experienced, often using good sense and practice, as Caregiver 7 mentions: the difficulty in providing the care... the doubts which I have and how to deal with this, we work it out on our own... It's very difficult without help... but, to see her recuperating... for sure...no decision as such was made about her care. I said, I'll take care of her, and that was that! You know, because... everybody works, and can't leave their jobs. I decided to quit everything else,... I'll care for her, end of discussion....

The educative approach remains incipient for the families and the patients who suffered strokes, as does the management of this care. There is, therefore, a need to implant educational models so that the patients and their families may provide the care, in the period of transition from hospital to the home(21), in a real context for each family, with its culture, beliefs and relationships with the elderly person, in this prolonged period of care.

In the light of epidemiological data referring to chronic illnesses in Brazil, it is necessary to implement the policy of referral and counter-referral, in the face of difficulties in the process of caring; the family is upset and the conflicts appear in the face of the difficulties in coping with this process. 


\section{Typology 3: Impact and acceptance of the limitations}

Caring for a family member is part of Brazilian culture, although one may observe a new family context which is taking shape. The social functions of the family are in the process of changing, considering the country's sociodemographic aspects. In addition to this, the policies for inserting women into the workplace end up compromising the care process, as the majority of caregivers are women, and some of them had to ...end up abandoning my job, because there was nobody to care for my mother.... (Caregiver 9).

The health services for elderly people being cared for at home remain inefficient, a fact confirmed in the present study on the elderly. Thus, the family itself, without preparation, "tries" to reorganize so as to deal with this process, as Caregiver 2 reports ...the impact on the family as a whole, because of the fact that he had a stroke, everybody was terrified, everybody here, you know, they call me... ...We have been married for many years.... this means that when you live with somebody for a long time... that person's pain is yours... Everybody's life changed after the stroke... because he can't walk, or talk, because of everything, because everything changes, change comes, it comes along with the stroke.... The impact of the elderly person's limitations may have repercussions on family relationships: ...this had an impact on the entire family... it was a fright! It was a fright because he was really well, apparently he was really well. He never complained of anything, and suddenly he fell in the bathroom, it was such a fright... this situation had an impact on the family relationships, because of his limitations (Caregiver 10). However, it was observed that in the structured families and with good relationships, the process is dynamic ...but I think that we're calming down, I can feel this too, I myself am much calmer! But I still think the insecurity affects us because it's all very new, you know? However, I feel, like my sisters, that we're restructuring...it's because time is passing... (Caregiver 9).

Discharge from hospital should be considered a special moment for producing continuity of the treatment and care, thus establishing the system of conter-referral, constructing in this way the care pathway, with the family's participation in this network ${ }^{(16)}$. After discharge from hospital, the primary care system proposed by the Unified Health System, still does not function effectively, although the integrality of care can only be obtained in a network ${ }^{(16)}$ which must be woven in the practice, involving the family.

The chronic illnesses, principally CVA, are permeated by social, economic, political and cultural problems, and are inserted in the agenda of federal and state public policies. However, what may be ascertained is that the family is on the margins of this "care network", undertaking actions in line with its experiences, and that it devises "trial and error" strategies, in addition to family discussions and the experiences of others. The ways of caring differ according to the elderly persons' needs, to the family setting and structure, and to each family's knowledge; however, each family uses certain strategies such as patience, love, unity, desire to share and learning from the everyday.

The clinical practice of the nurse providing care to the health system user who has been discharged from hospital to the home makes it important to implement the proposal of articulating care networks, to understand the family caregiver's values, beliefs and care practices for the elderly person; thus, in the light of the care typologies presented in this research, it is important that Primary Care should broaden this process of care.

In the face of the difficulties families have in caring for the elderly at home, and of the redefinition of the nurse's practice, a Model of Care for the Elderly After CVA is proposed. It is proposed to systematize the care for the elderly from the moment of discharge from hospital, with an evaluation model to identify the needs and to provide holistic care, according to each family's context, thus avoiding complications and re-hospitalizations. This plan must be devised by the team while the elderly person is still receiving inpatient treatment and preparing to be discharged, must be discussed with the family and forwarded to the Primary Care Center for the work of the nurse in the Family Health Strategy (FHS) team to be carried out (Figure 1). It involves the following stages:

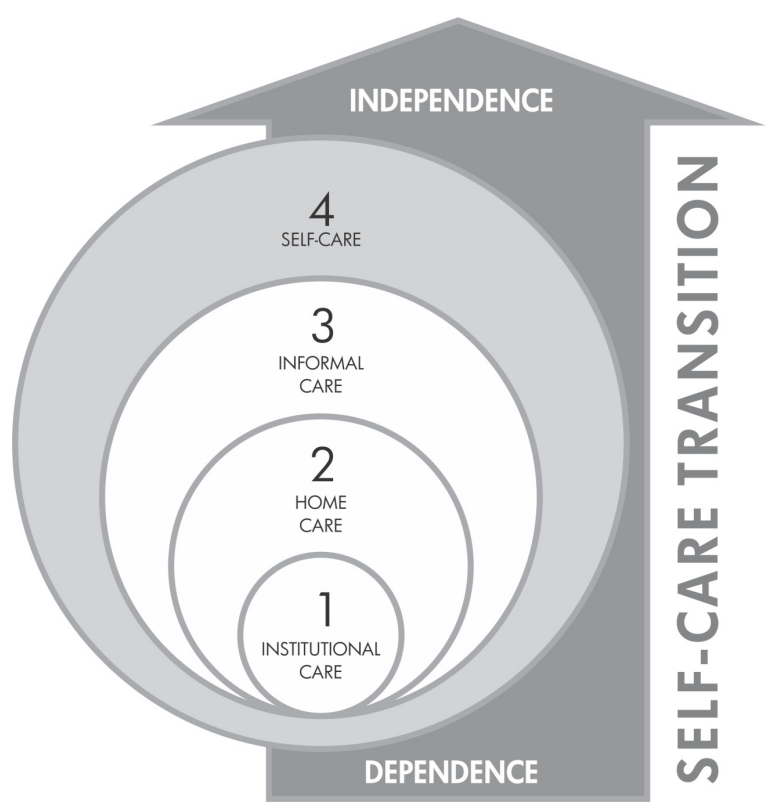

Figure 1 - Proposal for a Model of Care for the Elderly After CVA, 2011 
1. Institutional care: the phase of the transition which includes the appearance of the elderly person's dependence, the hospital care and the discharge home, always working with self-care. This is when the care plan for the elderly person at home is elaborated;

2. Home care: from the moment of contact with the family caregiver with the Primary Care Center, it is the responsibility of the FHS team to carry out the visit to evaluate elderly person, the conditions of the house and the family's knowledge so as to systematize the care, as well as refer them to other support networks should it be necessary. Hence, the clinic's knowledge is fundamental for evaluations, follow-up of care, supervision and education for the elderly and their families;

3. Informal care: this is related to the action of the family itself and of others who care for the elderly person. In this phase, the FHS must use resources from the community and must know each family's context well, for this process of the care. The care network must be widened, with the participation of other elements;

4. Self-care: the strategy of self-care must be incentivized starting from the period of inpatient treatment in hospital. This is when the nurse must systematize the individual care and propose strategies for self-care. On returning home, care activities and educational actions are strategies to be used and evaluated so that the dependency may be minimized until partial dependence and independence is reached, according to each person's conditions.

Integrality requires that the work of the primary care team recognizes the elderly person's needs and the family's care practices, as well as the resources available for this care, within the cultural context with its beliefs and values, which were constructed socially, both because of the ageing process and because of an illness which produces incapacities. It is, moreover, worth emphasizing the importance of the care's integrality, that is, the variety of services and their reach(22); in addition, support for education for the family to provide this care at home has to be considered a necessary practice. In the specific case of the elderly person after a CVA, the hospitalization is emergency treatment, but the care provided after discharge is more prolonged, the elderly persons' needs diverge in each situation, the families have distinct contexts and relationships, and the continuity and the integrality are compromised by the absence of the continuity of care.

According to the epidemiological data on CVA, both in developed countries and developing countries, there is an urgent need to study the evidence for the provision of care, in isolation from the social context of the health system. Hence, knowledge is needed on how this care process takes place, through a case study, that is, what "it interprets is the flow of social discourse and interpretation; thus, the interpretation involved means trying to save what was said in that discourse from a possible extinction and fixing it in researchable form"(12)

Considering this collocation, the application of proposals of care and the implementation of research showing evidence collaborate with the organization of health work and the integrality of care in networks; in addition to this, the nurse's clinical practice is in expansion because of the legal requirements professional practice in this category.

\section{Final considerations}

The elderly person who has suffered a CVA passes through stages, from treatment at the hospital level to care at home. The transition of this care is a time which presented difficulties for the families dealing with new situations, from everyday activities to those of greater complexity. The families, through the course of their lives, constructed typologies of care within the perspective of the culture which they themselves constructed. Thus, it falls to the health professionals to know these typologies and to propose models of care for the elderly, based on a care framework in which the culture of the care may be inserted in this process.

\section{References}

1. World Health Organization. World Health Report 2004: Changing History. Geneva, $(\mathrm{CH})$ : World Health Organization; 2004.

2. Mukherjee D, Patil CG. Epidemiology and the Global Burden of Stroke. World Neurosurg. 2011;76(6 Suppl):S85-90.

3. Strong K, Mathers C, Bonita R. Preventing stroke: saving lives around the world. Lancet Neurol. 2007;6(2):182-7.

4. Ministério da Saúde (BR). Banco de Dados do Sistema Único de Saúde - DATASUS [internet]. [acesso 15 jul 2012]. Disponível em: www.datasus.gov.br.

5. Rittman M, Faircloth C, Boylstein C, Gubrium JF, Williams C, Van Puymbroeck $M$, et al. The experience of time in the transition from hospital to home following stroke. J Rehabil Res Dev. 2004;41(3A):259-68.

6. Mackay J, Mensah G. The atlas of heart disease and stroke. Word Health Organization; 2004. [acesso 
01 ago 2011]. Disponível em: http://www.who.int/ cardiovascular_diseases/resources/atlas/en/.

7. Curioni C, Cunha CB, Veras RP, André C. The decline in mortality from circulatory diseases in Brazil. Pan Am J Public Health. 2009;25(1):9-15.

8. Pedreira LC, Lopes RLM, 2010. Cuidados domiciliares ao idoso que sofreu Acidente Vascular Cerebral. Rev Bras Enferm. 2010;63(25):837-40.

9. Bocchi SCM. Vivenciando a sobrecarga ao vir-a-ser um cuidador familiar de pessoa com acidente vascular cerebral (AVC): uma análise do conhecimento. Rev. Latino-Am. Enfermagem. 2004;12(1):115-21.

10. Chick N, Meleis AI. Transitions: a nursing concern. Chinn IP. Nursing research methodology. Boulder (CO): Aspen Publication; 1986. p. 237-57.

11. Farzan DT. Reintegration for stroke survivors. Home and community considertations. Nurs Clin North Am.1991;26(4):1037-48.

12. Geert C. A interpretação da cultura. Rio de Janeiro: LTC- Livros Técnicos e Científicos, 1989. 323 p.

13. Leininger $M$. Teoria de enfermagem transcultural. In: George J. Teorias de Enfermagem: os fundamentos para a prática profissional. Porto Alegre (RS): Artes Médicas; 1993. p. 285-99.

14. Appleton, J.V. Critiquing approaches to case study design for a constructivist inquiry. Qual Res J. 2002;2(2):80-97.

15. Braun V, Clarke V. Using thematic analysis in psychology. Qual Res Psychol. 2006;3(2):77-101.

16. Cecílio LCO, Merhy EE. A Integralidade do Cuidado como Eixo da Gestão Hospitalar. In: Pinheiro R, Mattos RA. Construção da Integralidade: cotidiano, saberes e práticas de saúde. $2^{a}$ ed. Rio de Janeiro (RJ): UERJ, IMS: Abrasco; 2003. p.197-210.

17. Rittman M, Boylstein C, Hinojosa R, Hinojosa MS, Haun J Transition Experiences of Stroke Survivors Following Discharge Home. Top Stroke Rehabil. 2007;14(2):21-31.

18. Matumoto S, Fortuna CM, Kawata LS, Mishima SM, Pereira MJB. A prática clínica do enfermeiro na atenção básica: um processo em construção. Rev. Latino-Am. Enfermagem. 2011;19(1):123-30.

19. Bull MJ. Managing the transition from hospital to home. Qual Health Res. 1992;2(1):27-41.

20. Schumacher KL, Meleis AI. Transitions: a central concept in nursing. Image J Nurs Ash. 1994;26(2):11927.
21. Cameron JI, Tsoi C, Marsella A. Optimizing stroke Systems of care by enhancing transitions across care environments. Stroke. 2008;39(9):2637-43.

22. Starfield B. Atenção primária: equilíbrio entre necessidades de saúde, serviços e tecnologia. Brasília (DF): Unesco, Ministério da Saúde; 2002. 710 p. 